\title{
京津冀城市群县域尺度生态效率评价 及空间格局分析
}

\author{
任宇飞 ${ }^{1}$, 方创琳 ${ }^{2 *}$ \\ (1. 首都师范大学资源环境与旅游学院, 北京 $100048 ; 2$. 中国科学院地理科学与资源研究所, 北京 100101)
}

\begin{abstract}
摘 要: 京津冀城市群地区是国家经济发展的战略核心区之一, 其经济发展与资源环境关系是近年来地理研究的重 点领域。本文以京津冀城市群县域为单元, 利用 PM $2.5 、 \mathrm{NO}_{2}$ 遥感反演等数据, 设计资源投人一经济效益一环境影 响复合生态效率评价指标体系, 构建县域单元生态效率评价模型, 并利用非期望产出 SBM 模型对生态效率进行了 评价, 运用空间自相关分析方法对生态效率的空间效应与空间关联模式进行了检验与分析。结果显示: (1)资源投 人、经济效益与环境影响格局存在明显时空分异, 高值区主要分布在京津唐三市及周边部分县区; 222006、2010、 2014 年 3 个时期京津冀城市群县域单元生态效率均值分别为 $0.324 、 0.305 、 0.347$, 总体水平较低, 并呈现先下降后 改善态势, 区位、自然本底条件是导致生态效率空间差异的主要原因。(3)全局 Moran's $I$ 指数分别为 0.2539 、 $0.3007 、 0.3088$, 表明县域单元生态效率存在空间正向集聚趋势; (4)县域单元生态效率正向集聚程度越来越显著, 邻 域单元生态效率差距则有所缩减。
\end{abstract}

关 键 词:生态效率;改进TOPSIS 模型;SBM 模型;空间关联模式;县域单元; 京津冀城市群

\section{1 引言}

京津冀城市群不仅是中国核心经济区的重要 组成部分(陆大道, 2015), 也是目前全国“5+9+6”城 市群建设新格局中的 5 个特大城市群之一(方创琳 等, 2016)。改革开放以来, 京津冀城市群社会经济 取得了快速发展, 但区域人口高度集中, 以及高耗 能、高污染、低收益的产业发展模式仍未得到根本 改变, 社会经济发展对资源的巨大需求与消耗, 导 致生态环境恶化等问题愈加凸显。近年来, 京津冀 城市群地区大面积、长时段的极端雾䨪天气屡见不 鲜, 区域“污染同受”不良现象频繁发生, 社会经济 发展引发的环境问题成为制约京津冀城市群健康 发展的重要因素。在党和国家提出将生态文明理
念全面融人城市发展以及京津冀协同发展上升为 国家战略的背景下, 量化及协调京津冀城市群经济 发展与资源环境间关系, 是面向国家战略需求, 对 推动地区社会、经济、生态的高效与可持续发展具 有至关重要的作用。

生态效率集中体现了经济发展与资源环境利 用关系, 可综合测度资源环境的利用程度及其与经 济效率、环境影响的协调程度。Burritt等(2001)提 出的生态效率概念, 兼顾经济活动的环境效益与经 济效益,其核心思想在于以较少的资源投人、较小 的环境代价创造较高的社会经济价值。针对生态 效率问题, 国内外相关文献主要集中在生态效率内 涵定义(Division, 2010)、测度指标体系及方法(Lin et al, 2010)、生态效率的收敛性及其影响因素(涂正

收稿日期: 2016-12; 修订日期: 2016-12。

基金项目:国家自然科学基金重大项目(41590840,41590842) [Foundation: Major Projects of the National Natural Science Foundation of China, No.41590840, No.41590842]。

作者简介: 任宇飞(1990-), 男, 甘肃兰州人, 硕士研究生, 主要从事城市群可持续发展研究,E-mail: renyuf@126.com。

通讯作者: 方创琳(1966-), 男, 甘肃庆阳人, 研究员, 主要从事城市地理、城市群发展与城镇化的资源环境效应等研究, E-mail: fangcl@igsnrr.ac.cn。

引用格式: 任宇飞, 方创琳. 2017. 京津冀城市群县域尺度生态效率评价及空间格局分析[J]. 地理科学进展, 36(1): 87-98. [Ren Y F, Fang C L. 2017. Spatial pattern and evaluation of eco-efficiency in counties of the Beijing-Tianjin-Hebei Urban Agglomeration[J]. Progress in Geography, 36(1): 87-98.]. DOI: 10.18306/dlkxjz.2017.01.009 
革等, 2011)、生态效率的空间差异特征(Yin et al, 2014)等。国外学者以微观的行业 (QuariguasiFrota- Neto et al, 2012; Egilmez et al, 2014)、企业 (Hahn et al, 2010)、工业部门(Arabi et al, 2014)为主, 而国内学者多以宏观层面的城市(李惠娟等, 2010)、 区域层面(Yu et al, 2013)为主。目前生态效率研究 主要包括以下 3 类: (1)根据研究单元的空间尺度及 其特性, 建立相应的评价指标体系, 通过成本效益 分析(cost-benefit analysis)、生命周期成本分析(life cycle costing)(Huppes et al, 2005)等方法将多指标集 成为单一指标, 对研究对象的生态效率进行测度, 其主要缺点在于指标体系的选取以及指标的综合 集成具有一定的随意性和主观性; (2)将城市视为有 机生物体, 通过能值分析(emergy analysis)(Li et al, 2011)、物质流分析 (material flow analysis) (Gurauskienè et al, 2011)、生态足迹(ecological footprint) (Cerutti et al, 2013)等方法评价城市经济发展过程 中物质与资源的转换效率。该方法的难点主要在 于构建指标体系受数据可获性影响较大, 由于数据 的缺失, 往往以典型行业、城市为研究对象, 如北京 市 (Zhang et al, 2011) 等; (3)利用数学模型进行求 解。基于城市经济一生态系统的复杂性, 此类研究 采用对数据进行加权处理的方法将不同维度的指 标进行集成, 因模型法可避免权重赋值的主观性, 是现阶段城市生态效率研究的主要手段。目前应 用较广泛的模型主要有 DEA(Yin et al, 2014)、UMM (Liu et al, 2010)、LCI(Frischknecht, 2010)、VSM (Plehn et al, 2012)、TOPSIS(韩瑞玲等, 2011)等。其 中DEA模型因其具有所需指标少、指标原始信息保 存完整等优势, 成为目前学术界使用较多的模型之 一。DEA 模型包括 CRS、VRS、SBM、三阶段DEA、 Malmquist 指数、超效率 DEA 模型等, 因 SBM 模型 能较好处理资源要素消耗过程中伴随的负向环境 污染产出(Huang et al, 2014), 得到了学界的广泛应 用。相关研究主要有: 潘丹等(2013)利用 SBM 模型 对 1998-2009 年中国30个省份农业生态效率进行 的实证分析; 关伟等(2015)运用非期望产出 SBM 模型对中国 1997-2012 年省际能源生态效率进行 测度, 分析能源生态效率的空间特征, 并用空间计 量模型分析其影响因素; 胡彪等(2016)采用产出 SBM模型对中国省域生态效率进行测度, 运用空间 自相关分析法分析了生态效率全局及局域的空间
差异。

总体而言, 上述研究逐渐从静态、定性现状分 析转向动态、定量趋势评价, 为进一步研究生态效 率奠定了基础。但以上研究忽略了地区更小尺度 的县域单元间要素空间关联特征对生态效率的影 响, 也缺乏对于特大城市群地区县域生态效率协调 发展状态的详细研究, 以及从大气污染角度出发对 生态效率进行评价。近期, Wachsmuth 等(2016)在 著名期刊“Nature”发表文章,认为对于未来城市可 持续发展研究, 应将视角从孤立的点状城市转向相 互联系紧密的面状城市区域,探讨经济、资源等要 素在全球或区域城市网络中的流动作用,即关注不 同城市区域间经济、资源等要素在地理空间中的溢 出效应所带来的诸多影响。作者认为, 社会经济要 素通过空间异质性、空间依赖性及空间集聚机制、 扩散机制发挥影响作用,并改变了城市生态效率的 空间格局。因而深人研究生态效率的空间作用机 制以及与经济互动关系, 对综合评价京津冀城市群 县域单元经济发展与资源环境关系具有重要的指 导意义。据此,首先构建大气污染制约下的生态效 率评价指标, 利用遥感数据与社会统计数据构建生 态效率分析数据库, 采用熵技术支持下的 TOPSIS 模型对资源投人、经济效益和环境影响进行综合集 成并进行评价; 其次,利用基于非期望产出的 SBM 模型对 2006-2014年京津冀城市群县级行政单元生 态效率进行测度; 最后, 运用空间计量模型验证生 态效率的空间效应。

\section{2 研究方法与数据处理}

\section{1 熵技术支持下的 TOPSIS 模型}

TOPSIS 模型又称 “逼近理想排序法”, 是距离 综合评价法之一。模型优点为可操作性和客观性, 对样本需求不大且结果合理(马雪芗等, 2016)。本 文依据生态环境定义将指标分为 3 类, 即资源投人、 经济效益、环境影响。采用熵技术支持下的 TOPSIS 模型进行综合集成。该模型是利用熵权法对传 统 TOPSIS 评价法中权重确定环节进行了改善, 其 主要计算步骤如下:

（1）构建评价指标体系矩阵 $(\boldsymbol{X})$ 。假设被评价对 象有 $m$ 个, 每个评价对象的评价指标有 $n$ 个, 构建判 断矩阵: 


$$
\boldsymbol{X}=\left(x_{i j}\right)_{m \times n} \quad(i=1,2, \cdots, m ; j=1,2, \cdots, n)
$$

式中: $i$ 为被评价对象; $j$ 为评价指标; $m$ 为评价对象 总数; $n$ 为评价指标总数。

(2) 采用极值法对指标矩阵标准化:

$$
\boldsymbol{R}=\left(r_{i j}\right)_{m \times n} \quad(i=1,2, \cdots, m ; j=1,2, \cdots, n)
$$

式中: $\boldsymbol{R}$ 为标准化后的评价指标体系矩阵; $r_{i j}$ 为第 $i$ 个被评价对象在第 $j$ 个评价指标上的标准值。

(3) 计算信息熵 $\left(e_{j}\right)$ :

$$
e_{j}=-k \sum_{i=1}^{n} p_{i j} \ln p_{i j}
$$

式中: $p_{i j}=\frac{x_{i j}}{\sum_{i=1}^{m} x_{i j}} ; k=\frac{1}{\ln m} ; p_{i j}$ 为矩阵 $\boldsymbol{R}$ 的第 $i$ 个被 评价对象的第 $j$ 项评价指标下的指标值比重。

(4) 定义指标 $j$ 的权重 $\left(w_{j}\right)$ :

$$
w_{j}=\frac{1-e_{j}}{\sum_{j=1}^{n}\left(1-e_{j}\right)}
$$

式中: $e_{j}$ 为指标 $j$ 的熵值。

(5) 计算规范化后的加权矩阵 $(\boldsymbol{Z})$ :

$Z=\left(z_{i j}\right)_{m \times n}, z_{i j}=w_{j} \times r_{i j}(i=1,2, \cdots, m ; j=1,2, \cdots, n)$

式中: $z_{i j}$ 为第 $i$ 个评价对象在第 $j$ 个被评价指标规范 化后的值。

(6) 确定最优解 $z_{i}^{+}$和最劣解 $z_{i}^{-}$:

$$
\left\{\begin{array}{l}
z_{i}^{+}=\max _{j}\left(z_{i j}\right)(i=1,2, \cdots m ; j=1,2, \cdots, n) \\
z_{i}^{-}=\min _{j}\left(z_{i j}\right)(i=1,2, \cdots m ; j=1,2, \cdots, n)
\end{array}\right.
$$

(7) 计算各方案与最优解 $\left(o_{j}^{+}\right)$和最劣解 $\left(o_{j}^{-}\right)$的 欧氏距离, 即 $s e p_{i}^{+}$和 $s e p_{i}^{-}$:

$$
\begin{aligned}
& \operatorname{sep}_{i}^{+}=\sqrt{\sum_{i=1}^{m} w_{i}\left(z_{i j}-z_{i}^{+}\right)^{2}} \\
& \operatorname{sep}_{i}^{-}=\sqrt{\sum_{i=1}^{m} w_{i}\left(z_{i j}-z_{i}^{-}\right)^{2}}
\end{aligned}
$$

(8) 计算综合评价指数 $\left(C_{i}\right)$ :

$$
C_{i}=\frac{s e p_{i}^{-}}{s e p_{i}^{+}+s e p_{i}^{-}}
$$

式中: $C_{i}$ 值越大, 表征评价对象越优。

\subsection{SBM 模型}

SBM 模型由 Tone(2001)提出和发展, 属于非径 向和非角度的 DEA 模型。SBM 模型通过将松弛变 量放人目标函数中, 弥补了传统 DEA 模型大多属于 径向和角度度量, 缺乏对投人产出松弛问题的考虑 的欠缺, 能更有效评价非期望产出下的效率问题 (涂正革等, 2011)。模型表达为:

$$
\rho=\min \frac{1-\frac{1}{N} \sum_{n=1}^{N} \frac{S_{n}^{x}}{x_{k^{\prime} n}^{\prime}}}{1+\frac{1}{M+I}\left\{\sum_{m=1}^{M} \frac{S_{m}^{y}}{y_{k^{\prime} m}^{t^{\prime}}}+\sum_{i=1}^{I} \frac{S_{i}^{b}}{b_{k^{\prime}}^{t^{\prime}}}\right\}}
$$

$$
\begin{aligned}
\text { s.t. } & \sum_{t=1}^{T} \sum_{k=1}^{K} z_{k}^{t} x_{k n}^{t}+S_{m}^{y}=x_{k^{\prime} n}^{t^{\prime}},(n=1, \cdots, N) \\
& \sum_{t=1}^{T} \sum_{k=1}^{K} z_{k}^{t} y_{k m}^{t}-S_{m}^{y}=y_{k^{\prime} m}^{t^{\prime}},(m=1, \cdots, M) \\
& \sum_{t=1}^{T} \sum_{k=1}^{K} z_{k}^{t} b_{k i}^{t}+S_{i}^{b}=b_{k^{\prime} i}^{t^{\prime}},(i=1, \cdots, N) \\
& z_{k}^{t} \geqslant 0, S_{n}^{x} \geqslant 0, S_{m}^{y} \geqslant 0, S_{i}^{b} \geqslant 0,(k=1, \cdots, K)
\end{aligned}
$$

式中: $\rho$ 代表效率值; $N 、 M 、 I$ 分别代表投入、期望产 出与非期望产出的个数; $n 、 m 、 i$ 分别代表投人、期望 产出与非期望产出的指标类型; $t$ 表示时间; $x, y, b$ 表示松弛变量类型; $S_{n}^{x} 、 S_{m}^{y} 、 S_{i}^{b}$ 代表投人、期望产 出与非期望产出的松弛向量 $; x_{k^{\prime} n}^{\prime} 、 y_{k^{\prime} m}^{t^{\prime}} 、 b_{k^{\prime} i}^{t^{\prime}}$ 代表第 $k^{\prime}$ 个决策单元在 $t^{\prime}$ 时期的投人产出值; $z_{k}^{t}$ 代表决策 单元的权重。目标函数 $\rho$ 关于 $S_{n}^{x} 、 S_{m}^{y} 、 S_{i}^{b}$ 严格单调 递减, $0<\rho \leqslant 1$; 当 $\rho=1$ 时, 决策单元效率值位于 DEA 前沿面; 当 $\rho<1$ 时, 决策单元存在效率损失。

\section{3 空间自相关分析法}

空间自相关是空间单元属性值集聚程度的表 征。全局空间相关测度研究区域内所有空间对象 的总体关联程度、空间分布模式及其显著性，全局 Moran's $I$ 指数为:

$$
I=\frac{\sum_{i=1}^{n} \sum_{j \neq 1}^{n} \boldsymbol{W}_{i j}\left(x_{i}-\bar{x}\right)\left(x_{j}-\bar{x}\right)}{\sigma^{2} \sum_{i=1}^{n} \sum_{j \neq 1}^{n} w_{i j}}
$$

式中: $x_{i}$ 为城市 $i$ 的观测值; $n$ 为观测值数目; $\bar{x}=\frac{1}{n} \sum_{i=1}^{n} x_{i}, \sigma^{2}=\frac{1}{n} \sum_{i=1}^{n}\left(x_{i}-\bar{x}\right)^{2}$; 空间权重矩阵 $\boldsymbol{W}_{i j}$ 为二 元邻接矩阵。式(12)为 $Z$ 检验统计量, 其中 $E(I)$ 为期 望, $\operatorname{Var}(I)$ 为方差。

$$
Z=\frac{1-E(I)}{\sqrt{\operatorname{Var}(I)}}
$$

式中: 如果 $I$ 显著为正,则表明存在正向空间相关 性,生态效率值较高(低)的区域在空间上呈集聚形 态。全局自相关假定空间同质,无法反映局部集聚 特征,需要进一步进行局部空间自相关分析。局部 空间自相关反映每个城市与相邻城市之间的空间 关联程度,局部 Moran's I 指数为:

$$
I_{i}=z_{i} \sum_{i \neq j}^{n} w_{i j} z_{j}
$$


式中: $I_{i}$ 为城市 $i$ 的局部 Moran's $I$ 指数; $Z_{i}$ 为 $Z$ 标准化 后城市 $i$ 的生态效率值; $\boldsymbol{W}_{i j}$ 为空间权重矩阵。局部 Moran's I指数为正(负)表示相似(异)类型属性值要 素空间邻近, 绝对值越大表示邻近程度越高。局部 空间自相关可识别局部单元属性在相邻区域中的 自相关性, 将集聚类型划分为 H-H、H-L、L-L、L-H 集聚 4 种类型。

\section{4 研究单元、数据来源和评价指标构建}

\subsection{1 研究单元及数据来源}

中国行政区划中市县级行政单元包括县(含自 治县)、县级市、市辖区 3 个类别。本文选择京津冀 城市群地区共 153 个县级行政单元为研究对象, 研 究时段为 2006 、2010 和 2014年。县(含自治县)和县 级市数据主要来源于《中国区域统计年鉴(2007、 2011)》、《中国县(市)社会经济统计年鉴(2007、2011、 2015)》、各县(市)历年《国民经济和社会发展统计公 报》以及北京市、天津市、河北省统计年鉴和一手调 研资料, 市辖区数据主要通过《中国城市统计年鉴 $(2007 、 2011 、 2015) 》$ 获取。大气污染物 PM2.5、 $\mathrm{NO}_{2}$ 数据来源于大气成分分析组织(ACAG)利用美国国 家航天航空局(NASA) 提供的 MODIS 、MISR 以及 SeaWIFS 等遥感数据, 对气溶胶光学厚度(AOD)进 行合并计算反演出的地表大气污染数据, 栅格分辨 率为 $1 \mathrm{~km}$ (van Donkelaar et al, 2016; Geddes et al, 2016)。

\subsection{2 生态效率评价指标}

在对以往生态效率相关定义进行梳理、辨析的 基础上, 本文定义生态效率为: 城市社会经济发展 中所创造的期望经济效益与非期望环境影响产出 和与城市有效利用的资源投人的比率, 即 生态效率 $=\frac{\text { 经济效益产出 }+ \text { 环境影响产 }}{\text { 实际利用资源投人 }}$ 。城市经 济生产活动是建立在一定要素投人基础上创造有 形物质和无形物质的活动, 人力与资本投人是生产 活动的基本指标。城市经济活动通过利用各类资 源投人转化为商品和服务产生经济价值, 国民生产 总值、工业生产总值是考察城市经济效益的关键指 标。经济发展和城镇化水平的不断提升无疑推动 了社会物质财富积累和人民物质生活水平的不断 提高, 但也导致了大气污染物浓度不断上升 $(\mathrm{Li}$ et al, 2016), 空气污染成为阻碍地区可持续发展的主 要因素之一。因此, 基于生态效率定义以及数据可
得性等原则, 本文利用遥感反演数据构建大气污染 制约下的特大城市群县域单元生态效率评价指标 体系(表 1 )。投人要素为反映城市经济活动最基本 的人力及资本要素投人; 期望经济效益产出反映城 市经济活动生产出的价值量, 包括 GDP、工业总产 值; 非期望环境影响为空气污染主要成分, 包括 $\mathrm{PM} 2.5 、 \mathrm{NO}_{2}$ 浓度值。此外, 本文还考虑到了政府资 本, 政府财政预算收支是政府为了实现其政治、经 济和社会方面的职能所必须调动的各类资源的价 值量, 对于城市生态效率具有积极的影响和调控 作用。

\section{3 京津冀城市群县域尺度生态效率测 度与评价}

\section{1 生态效率投入产出指标时空分异}

本文采用熵技术支持下的 TOPSIS 模型将生态 效率指标分别集成为综合资源投人、经济效益、环 境影响指数, 通过 Jenks 最佳自然断裂法对集成结 果进行分类并保证不同时段分类标准一致,以对集 成综合指数进行时空格局分析(为便于展示, 对综 合集成结果乘以 100)。

\subsection{1 县域资源投人时空分异}

如图 1 所示, 京津冀城市群县域单元资源投人 格局存在明显的时空分异, 且呈明显的高值区与低 值区分化格局。从时序格局变化来看,京津和位于 燕山山前平原地区的唐山市辖区在整个研究时段 中均为高值区, 周边县域资源投人水平随时间呈相 对上升趋势,表明该地区依靠京津唐市辖区较强的 社会经济发展实力,使得要素集聚效应不断强化, 对周边县区的辐射带动作用不断增强。第二类高 值区为河北省沿海地区,包括秦沧辖区及周边县

表 1 京津冀城市群县域单元生态效率测度指标体系

Tab.1 Evaluation indicators of eco-efficiency in counties of the Beijing-Tianjin-Hebei Urban Agglomeration

\begin{tabular}{lll}
\hline 指标类型 & \multicolumn{1}{c}{ 一级指标 } & \multicolumn{1}{c}{ 二级指标 } \\
\hline 投人指标 & 资本要素投人 & 全社会固定资产投资总 \\
& & 值、政府财政预算支出 \\
& 人力投人 & 年末人口总数 \\
产出指标 & 经济效益(期望产出) & GDP、工业生产总值、政 \\
& & 府财政预算收人 \\
& 环境影响(非期望产出) & $\mathrm{PM} 2.5$ 浓度、 $\mathrm{NO}_{2}$ 浓度 \\
\hline
\end{tabular}


区。该区域位于沿海新兴增长区域, 是国家重点优 化开发区, 也是京津城市功能拓展和产业转移的重 要承接地。2010年以后, 该区域投入规模得到明显 提升。第三类高值区位于冀中南地区。石保邢邯 地区是河北省工业化水平、基础设施配套程度、科 技文化资源集聚规模相对较高的区域,其资源投人 指数在整个研究时段中不断上升, 四市市辖区周边 县域单元资源投人指数由低值区向高值区转变明 显。特别是石家庄地区伴随省会城市地位的不断 提升, 以及鹿泉、奕城和菜城的撤县设区, 资源投人 规模得到进一步加大, 对周边地区的辐射作用得到 一定提高。

资源投人低值区主要位于河北省北部及西南 部地区。北部地区多为高原山地, 为国家及省级重
点生态功能区, 是保障京津冀生态安全的重要区 域, 因此开发强度较低, 资源投人相对较少。西南 部县域单元主要为农产品主产区, 是国家黄淮海平 原农产品主产区的重要组成部分, 工业化与城镇化 建设强度低,因此资源投人同样相对较少。

\subsection{2 县域经济效益空间分异}

京津冀城市群县域经济效益格局存在明显的 空间分异,经济效益由沿海地区向内陆地区逐步递 减,格局随时间基本保持稳定(图 2)。第一类高值区 分布在京津地区以及河北省沿海地区。京津市辖 区作为京津冀城市群的两大核心, 发展起步早, 经 济本底雄厚,经济效益远远高于其他地区。河北省 沿海地区包括唐、秦、沧三市辖区及周边部分县区, 该区域经济发展区位条件优越,工业基础较为雄
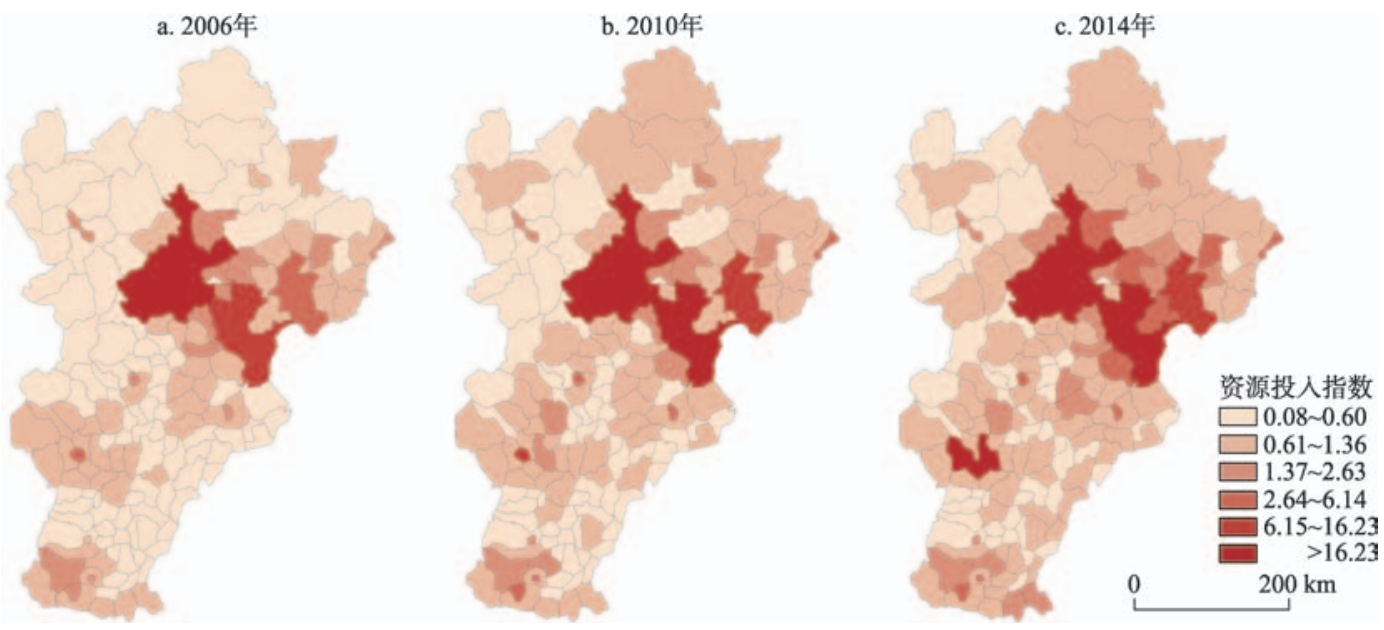

图 1 2006-2014年京津冀城市群县域资源投人指数时空分异格局

Fig.1 Spatiotemporal patterns of resource input in counties of the Beijing-Tianjin-Hebei Urban Agglomeration, 2006-2014
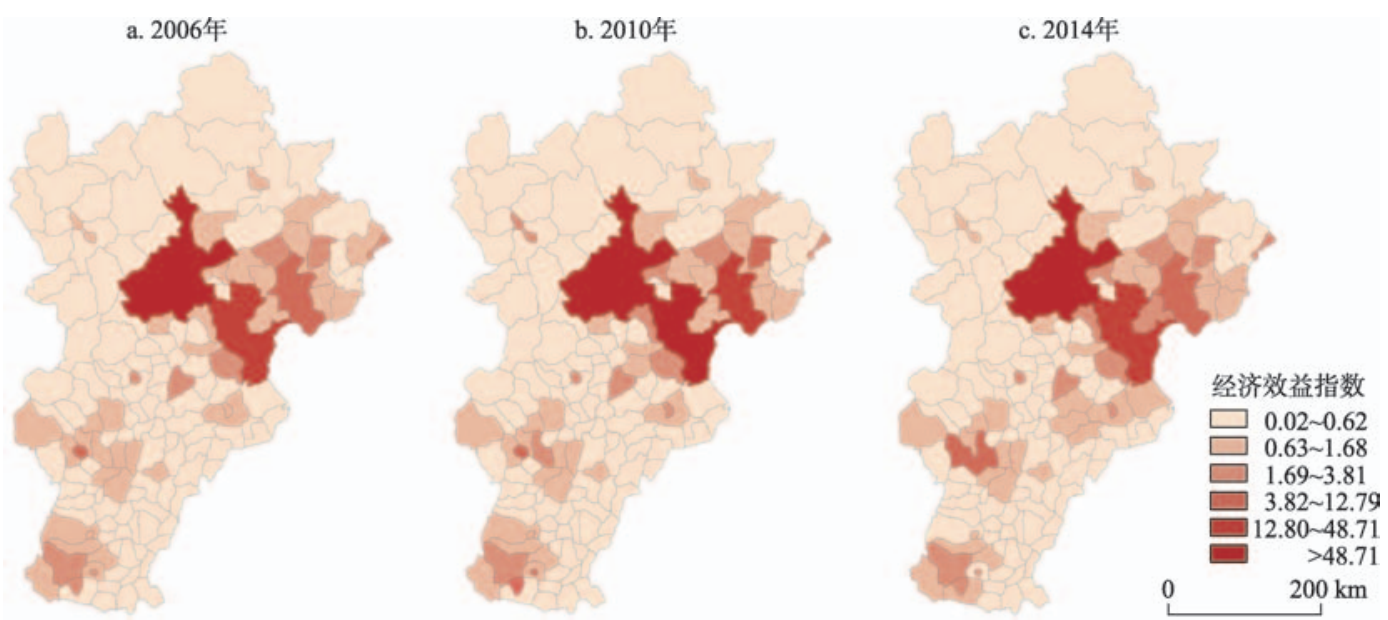

图 2 2006-2014年京津冀城市群县域经济效益指数时空分异格局

Fig.2 patiotemporal patterns of economic benefit in counties of the Beijing-Tianjin-Hebei Urban Agglomeration, 2006-2014 
厚, 经济发展模式具有一定的外向型特征, 经济效 益相对较高。第二类高值区包括冀中南地区的石、 邯两市辖区及周边县区, 此区域在河北省内工业化 发展水平相对较高, 现代服务业发展势头强劲, 集 聚一批装备制造、石油工业、冶金等重工业类型产 业, 经济效益相对周边地区较高。

经济效益低值区则主要分布在河北省西北部 与西南部。西北部坝上高原山地区和冀北燕山山 区为重点生态功能区, 是京津和冀东地区的生态屏 障, 产业发展类型与规模受到一定约束, 因此经济 效益较低。西南部的黑龙港中北部部分平原地区 是国家粮、棉、油等农产品重要的集中产区, 农业地 位突出, 经济效益产出同样较低。

\subsection{3 县域环境影响时空分异}

京津冀城市群县域环境影响指数格局呈明显 的时空分异, 但不同于资源投人和经济效益的空间 格局, 呈大范围、连片菖延分布的空间特征(图 3)。 第一类高值区主要分布在津唐地区, 该区经济发展 水平与资源投人与经济效益均相对较高, 近年来随 着城市与工业规模的不断扩大, 环境与社会经济发 展矛盾愈加凸显。2006-2010年间, 津唐市辖区及 周边部分县域单元环境影响指数呈上升趋势, 成为 沿海环境污染核心区; 北京市辖区及周边县域单元 环境影响指数则保持稳定态势, 污染水平相对周边 县区较低。2010-2014年间, 天津市辖区环境影响 指数有所下降, 环境污染问题得到一定程度缓解, 但唐山地区县域单元环境污染情况依然较重, 显然 与唐山市周边钢铁等重工业企业分布密集、产能集
中度过高有关。由于重工业高耗能、高排放的特性 使得该区成为环境污染聚集区。第二类高值区主 要分布在冀中南地区。从整个研究时段来看, 石、 邯两市辖区环境影响指数始终较高, 周边邻近县区 环境影响指数随时间上升趋势明显, 尤其以石家庄 为核心向保定、沧州方向逐渐出现连片高值区。该 区环境影响指数高的现状主要是由于冀中南地区 产业结构粗放、产业层次偏低所致。冀中南地区第 一产业和传统工业规模大, 而新兴产业规模相对较 低, 工业仍以钢铁、建材煤化工等资源密集型传统 工业为主, 主导产品以钢铁、原煤、水泥、原盐、化学 原材料等为主,生产过程中因化石燃料燃烧产生的 空气污染物排放量始终较高。

低值区则分布在河北省北部及西北部地区, 这 与资源投人、经济效益的低值区格局保持一致。西 北部坝上高原山地区和冀北燕山山区绿色农产品 加工业、生态产业发展较快。近年来, 该区大力发 展生态旅游、休闲度假服务业以及建设绿色农产品 和生态产业基地, 因此空气污染物排放量相对较 少, 环境影响指数始终较低。

\section{2 县域生态效率总体评价}

根据评价指标体系，分别选择2006、2010、2014 年, 将京津冀城市群的 153 个县域单元作为决策单 元, 计算出 3 个时期京津冀城市群县域生态效率值 (图 4)。计算结果表明:3个时期京津冀城市群县域 单元生态效率总体水平较低,均值分别为 0.324 、 $0.305 、 0.347$,呈现先下降后改善态势。在研究时段 均达到DEA效率最优前沿面的有京津唐市辖区以
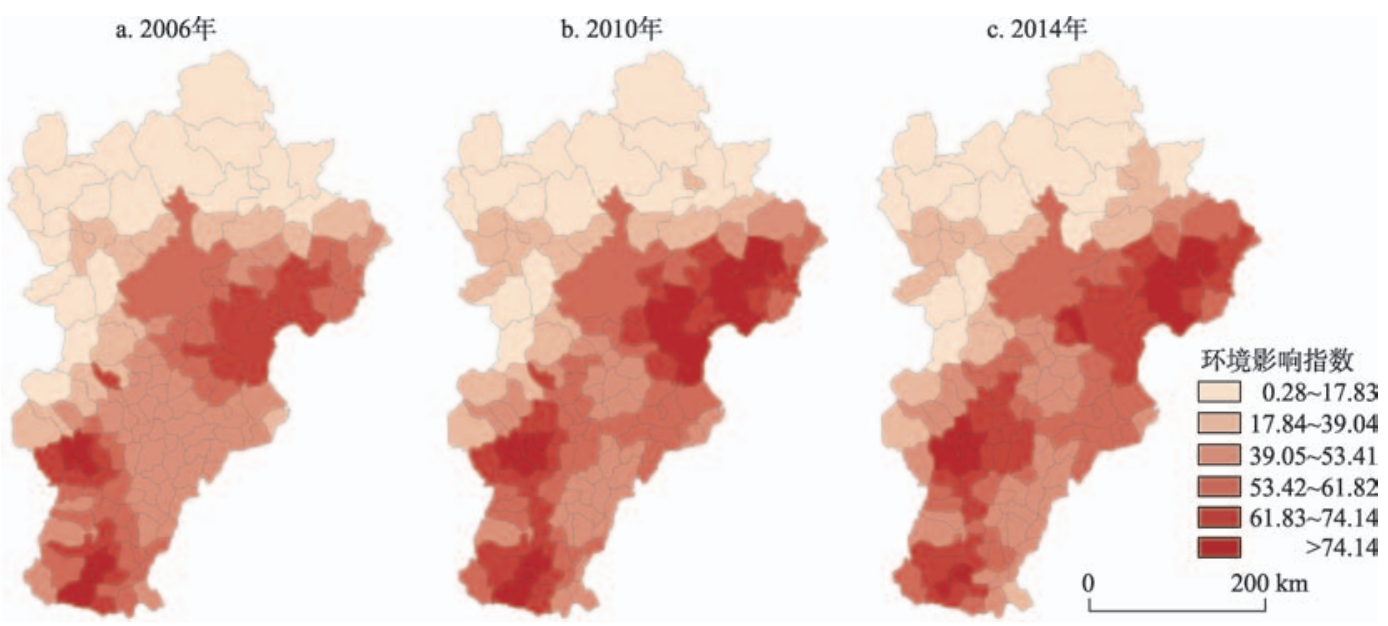

图 3 2006-2014年京津冀城市群县域环境影响指数时空分异格局

Fig.3 Spatiotemporal patterns of environmental pollution in counties of the Beijing-Tianjin-Hebei Urban Agglomeration, 2006-2014 

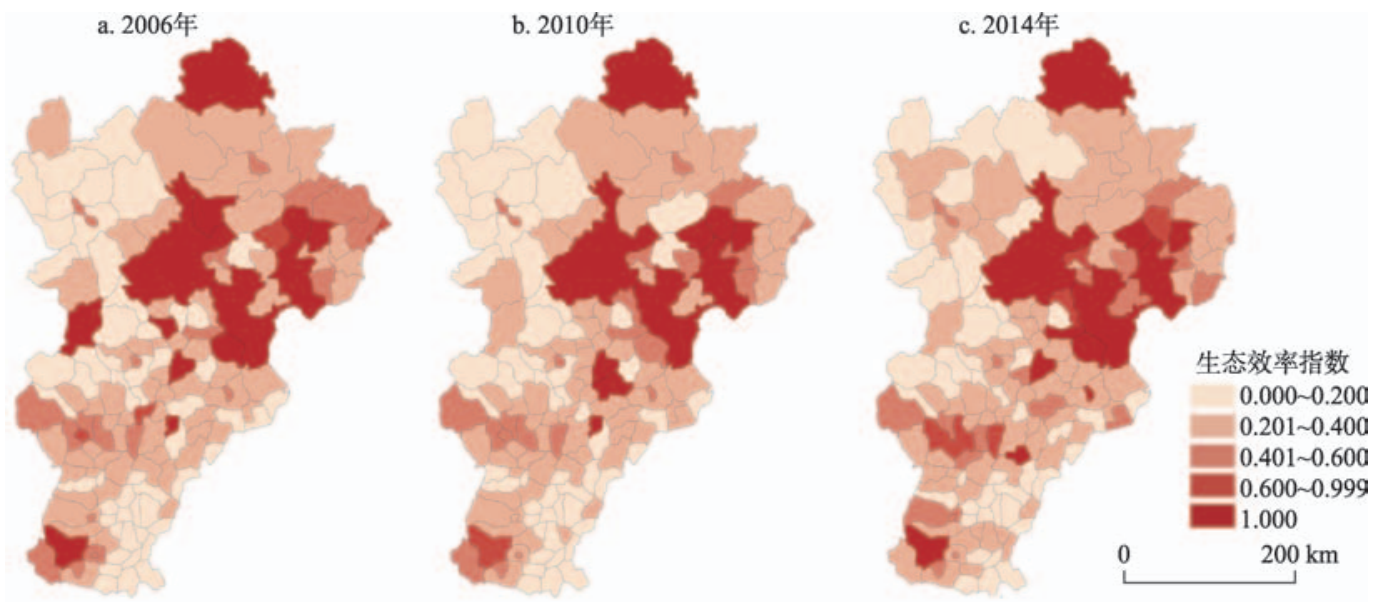

图 4 2006-2014年京津冀城市群县域生态效率空间分异

Fig.4 Spatiotemporal patterns of Eco-efficiency in counties of the Beijing-Tianjin-Hebei Urban Agglomeration, 2006-2014

及迁安市、任丘市、围场满族蒙古族自治县。从 3 个 研究时段生态效率值分类后数量及占比情况来看: (1) 县域单元数量占比最多的区间为 0.200 以下和 $0.201 \sim 0.400$ 。其中, 2006 年与 2010 年生态效率值 在 0.200 以下的县域单元数量相同, 均为 55 个, 占总 数的 $36 \%$ 。2014年该区间单元数量有所下降, 为 45 个, 占总数的 $29 \%$, 与之前相比下降 $7 \%$; (2)生态效 率值在 $0.201 \sim 0.400$ 之间的县域单元数量在研究时 期分别为 $62 、 66 、 69$ 个, 占总数的 $40 \% 、 43 \% 、 45 \%$, 2014年该区间单元数量有所上升; 30.401 0.999 区 间县域单元数量分别为 $23 、 22 、 24$ 个, 占总数的 $15 \% 、 14.3 \% 、 15.7 \%$, 整体变动幅度较小; (4)达到 DEA 效率前沿面的县域单元数量分别为 $13 、 10 、 12$ 个, 占总数的 $8.5 \% 、 6.5 \% 、 7.8 \%$, 整体变化幅度同样 相对较小。综上所述, 生态效率值均为 1 的县域单 元数量稀少, 多数单元生态效率值位于 0.400 以 下。县域单元生态效率值整体得到改善的原因为 0.200 以下区间的县域单元数量有所减小, 低值区 县域单元生态效率值得到一定提高。

\section{3 生态效率时空分异特征与影响因素}

在分析生态效率空间分异特征的基础上, 将其 值与资源投人、经济效益、环境影响指数进行对应 分析, 以发现生态效率值与投人产出指标的协调关 系。如图 4所示, 生态效率各区间空间格局分异明 显, 格局随时间变化相对稳定。从生态效率值分类 结果来看: (1)生态效率值在 0.200 以下的县域单元 主要分布在河北省西北部坝上高原山地区、冀北燕 山山区以及河北省西南部地区。此类县域位于重 点生态功能区和国家农产品主产区, 距离区域核心
城市空间距离较远。受核心市辖区辐射带动力弱 以及产业发展类型与规模受限的约束, 使得其投人 要素集中度、期望经济效益和非期望环境产出均相 对较低。生态效率值维持较低水平的原因主要来 自经济效益过低; (2)生态效率值在 0.201 0.400区间 的县域单元主要分布在张承地区和冀中南地区。 位于张承地区的县域单元社会经济发展水平较低, 产业结构层次偏低,多以资源密集型产业为主,例 如农业等。因资源投人水平偏高, 使得经济产出效 率偏低,一定程度上拉低了生态效率水平。位于冀 中南地区的县域单元社会经济发展水平相对较高, 县域产业多以重化工为主, 其特点是资源投人水平 和期望经济效益产出差距较小, 但在经济发展过程 中产生了相对较高的非期望环境污染,生态效率值 较低; 3)生态效率值在 0.401 0.999 区间的县域单元 主要分布在区域核心、与中心城市的邻接地区。因 其离中心城市较近, 受到一定程度的辐射带动作 用, 城市经济发展规模较大, 因此经济效益相对较 高。但是, 其产业结构仍然以第二产业为主, 受生 产技术水平等因素的影响,致使一定的资源投人产 出了较高的非期望环境污染物, 造成了生态效率损 失; (4)生态效率值为 1 , 即达到 DEA 前沿面的县域 单元, 具体包括区域核心京津唐市辖区以及迁安 市、任丘市等。唐山市辖区经济发展起步早、工业 基础雄厚, 较高的资源投人产出了大量的期望经济 效益, 经济产出能力在一定程度上弥补了产出较高 非期望环境污染物带来的生态效率损失。北京市 辖区、天津市辖区、迁安市等单元则利用一定的资 源投人产生了较高的经济效益, 且污染产出呈降低 
趋势, 资源投人、经济效益和环境影响三者间关系 达到协调、高效的关系, 表现出理想的可持续发展 状态。

综上所述, 从 3 个时期京津冀城市群县域生态 效率空间格局总体概况来看, 位于沿海及平原地区 的核心城市市辖区及其周边县域单元的生态效率 值普遍高于位于山区的县域单元生态效率值, 中心 城市辐射带动效应与自然本底条件对生态效率具 有一定程度的影响。通过分析县域单元生态效率 与资源投人、经济效益和环境影响指数的协调关 系, 发现经济发展越好的县域单元生态效率值越高 的规律和存在一定的 “中心一外围”现象。此外, 县 域单元生态效率值偏低的原因有 2 个: 一是受一定 资源投人下产出的经济效益偏低影响,包括冀西北 和东南部分县域单元; 二是因经济生产过程中排放 的污染物对环境影响偏高, 包括冀中南部分县域 单元。

\section{4 京津冀城市群县域尺度生态效率的 空间关联效应}

\section{1 生态效率的全局关联格局}

对 2006、2010、2014 年京津冀城市群内 153 个 县域单元的全局自相关 Moran's $I$ 指数值进行计算 (表 2), 再对 2006、2010 和 2014 年的 Moran's I 指数 经 999 次蒙特卡罗模拟,发现 Moran's I指数在 $0.1 \%$ 的显著水平上, 3 个时期都呈正的空间相关性, 即生 态效率高值集聚和低值集聚的空间特性。2006年 以来, 全局 Moran's $I$ 指数依次为 $0.2539 、 0.3007$ 、 0.3088 , 呈出不断上升趋势, 表明生态效率正向集聚 现象逐渐增强。同时表明,各单元的生态效率不仅 与该区域的经济发展水平等因素有关,还与周围邻

表 2 2006-2014 年京津冀城市群县域单元生态效率 全局自相关 Moran's I指数

Tab.2 Global spatial autocorrelation index of ecoefficiency in counties of the Beijing-Tianjin-Hebei Urban

Agglomeration, 2006-2014

\begin{tabular}{cccc}
\hline 年份 & 2006年 & 2010 年 & 2014年 \\
\hline$I$ & 0.2539 & 0.3007 & 0.3088 \\
$E(I)$ & -0.0066 & -0.0067 & -0.0067 \\
$Z(I)$ & 4.69 & 5.65 & 5.87 \\
\hline
\end{tabular}

域单元生态效率相关。

\section{2 生态效率的局部关联格局}

本文选用Moran 散点图绘制 LISA集聚图来描 述效率局部空间异质性特征。根据县域单元生态 效率在其相邻区域中的自相关性, 可将其集聚类型 分为 4 类: (1)第一类为 “ $H-H$ ”聚集区,县域单元自身 和周边地区的生态效率值均较高, 两者空间差异程 度小; 2第二类为“H-L”聚集区,县域单元自身生态 效率较高, 周边地区则较低, 两者空间差异程度相 对较大; (3)第三类为 “L-L”聚集区,县域单元自身和 周边地区的生态效率均较低, 两者空间差异程度较 小; (4)第四类为 “ $\mathrm{L}-\mathrm{H}$ ”聚集区, 县域单元自身生态效 率较低, 周边地区较高, 两者空间差异程度较大。 结合 Moran散点图和局部Moran's I指数, 基于 Geo$\mathrm{da}$ 平台,绘制了 $2006 、 2010$ 年和 2014 年京津冀城市 群各县域单元生态效率的 LISA 集聚图(图 5)。由 图 5 可知, 3 个时期正相关模式(H-H、L-L 关联模式) 的县域单元数量呈上升趋势, 表明京津冀城市群县 域单元生态效率的正向集聚程度越来越显著。此 外, 自 2006 年以来, H-L 关联区和 L-H 关联区的数 量呈现出略有下降的态势, 邻域单元生态效率差距 有所缩减。

(1) H-H 关联区。此类型区域主要集中在沿海 和冀中南地区。自 2006 年开始, 3 个时期沿海地区 的天津市辖区和迁西县正向集聚现象均显著,该区 域所在的沿海区域是京津冀城市群中最大区位优 势板块, 也是带动城市群社会经济发展的增长极, 形成一个显著的生态效率高值空间集聚区。位于 天津西北部方向的青龙满族自治县则逐渐退出这 一类型,变为 L-H关联区,生态效率明显降低, 成为 高值区中的低谷。冀中南地区的 H-H 关联区则表 现为一定的转移特征, 2006 年属于 H-H 关联区有冀 南地区的涉县; 2010 年冀中南地区无 H-H 关联区 域,2014年涉县以及冀中地区的晋州市进人这一类 型。晋州市邻近有石家庄市辖区、辛集市等,涉县 周边拥有邯郸市辖区、武安市辖区, 这类区域是京 津冀地区的次级中心区域,同样形成一个较显著的 生态效率高值集聚区。

(2) H-L 关联区。此类型区域空间分布格局比 较稳定,随时间数量有所下降。2006年该类型主要 集中在张家口市辖区、涞源县、高碑店市、清河县; 2010年 H-L 关联区的城市主要有张家口市辖区、涞 

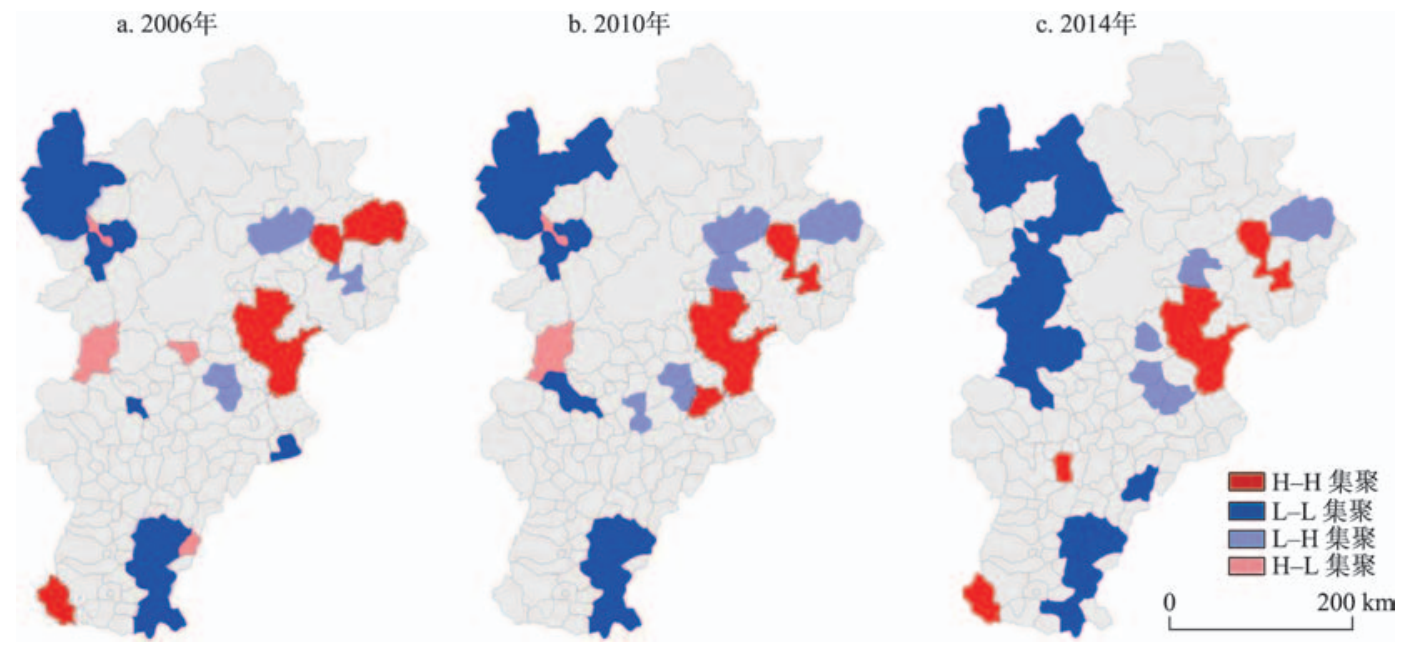

图 5 2006年、2010年和 2014 年京津冀城市群县域单元生态效率的 LISA集聚分布图

Fig.5 LISA cluster map of eco-efficiency in counties of the Beijing-Tianjin-Hebei Urban Agglomeration, 2006, 2010 and 2014

源县; 2014 年无该类型关联区。可以看出, 自 2006 年开始, H-L 关联区的数量开始减少, 所有县域单元 逐渐退出这一集聚区, 涞源县则变为 $\mathrm{L}-\mathrm{L}$ 关联类 型。H-L关联区多位于重点生态功能区和农产品主 产区, 邻近单元经济发展水平均较低, 自然本底及 地理区位条件也不够优越。受此影响,该类关联区 由原来自身生态效率较高、周边生态效率较低、空 间差异大的地区变为自身和周边生态效率都比较 低的生态效率低值集聚地。

(3) L-H 关联区。此类型区域在 3 个研究时期 内在空间上基本保持稳定, 数量有所增加, 主要包 括京津唐周边县区。此类空间分布格局一定程度 上说明京津唐市辖区发展过程中吸引了周边县区 的投人要素, 弱化了周边县区的经济发展, 强大的 “虹吸效应”加剧了周边县区 $\mathrm{L}-\mathrm{H}$ 关联型格局, 在一 定程度上制约了区域生态效率的提升。但是, 正因 为此类型县域单元邻近经济比较发达的京津唐市 辖区,具备了接受发达地区“扩散效应”辐射带动的 先决条件,若加之合理的政策及发展规划的引导, 该类型县域单元生态效率值提升潜力也较大。

(4) L-L 关联区。这类区域在空间范围上呈连 片连绵趋势, 空间分布格局上基本保持稳定, 主要 集中在冀西北张家口地区、燕山山区、太行山山区 以及冀西南部部分地区。这类关联区位于京津冀 城市群边缘地区, 发展基础薄弱, 经济发展实力较 差, 再加上距离核心城市较远, 社会经济发展有被 边缘化趋势, 与其相邻县域单元的生态效率值的差 距在不断在放大。今后, 应加大对 L-L 关联区产业
扶持力度以及政策、资金支持,促使其加快融人京 津冀城市群一体化发展的进程, 从而减弱此类型县 域单元生态低效率集聚趋势。

\section{5 结论与讨论}

根据生态效率定义, 资源投人与期望经济效益 产出、非期望环境污染产出三者间的相互关系决定 了区域生态效率的高低。本文通过设计资源投人 一经济效益一环境影响复合生态效率评价指标体 系, 构建了京津冀城市群县域单元生态效率评价模 型, 对县域单元 $2006 、 2010 、 2014$ 年资源投人、经济 效益、环境影响及生态效率进行了分析评价。最后 通过空间自相关分析方法, 对生态效率的空间效 应、关联模式进行了验证。主要结论如下:

(1) 资源投人高值区主要分布在京津唐三市及 周边部分区域以及河北省沿海地区,包括秦皇岛及 沧州市部分地区。资源投入低值区主要位于河北 省北部及西南部地区。经济效益则呈现由沿海地 区向内陆地区逐步递减趋势, 基本格局随时间相对 保持稳定。环境影响不同于资源投人和经济效益 的空间格局, 呈大范围、连片蔓延分布的空间特 征。其中高值区主要分布在河北省沿海地区和冀 中南地区, 低值区则分布在河北省北部及西北部地 区，与资源投人、经济效益的低值区格局保持一致。

(2) 从生态效率的计算结果、时空分异以及影 响因素分析来看, 京津冀城市群县域单元生态效率 总体水平较低, 均值分别为 $0.324 、 0.305 、 0.347$, 呈 
先下降后改善态势。京津冀城市群县域单元生态 效率改善贡献最大的为 0.200 以下低值区的县域单 元数量有所减少, 生态效率有一定程度的提高。生 态效率各分类区间空间格局分异明显, 格局随时间 变化相对稳定。从 3 个时期京津冀城市群县域生态 效率总的概况来看, 区位、自然本底条件是造成县 域单元生态效率空间差异的主要原因, 经济效益低 和环境影响高则是制约生态效率提高的主要因素。

(3) 对 3 个时期京津冀城市群内 153 个县域单 元的全局、局部空间自相关 Moran's I指数值进行计 算并进行检验,发现Moran's I指数在 $0.1 \%$ 的显著水 平上 3 个时期都呈正的空间相关性, 高值与低值集 聚具有逐渐增强趋势。说明各单元的生态效率不 仅与该区域的社会经济发展水平等因素有关, 还与 周围邻域单元生态效率相关。此外, 自 2006 年以 来, $\mathrm{H}-\mathrm{L}$ 关联区和 L-H 关联区的数量呈略有下降的 态势, 邻域单元生态效率差距有所缩小。

综上所述, 本文认为在以下 3 个方面的政策导 向将有利于提升京津冀城市群县域单元生态效率: (1)加强京津唐市辖区对周边以及沿海县域的辐射 带动作用, 加快人力、资本、技术等要素的外溢速 度, 强化周边及沿海县域要素集聚能力, 推动产业 结构向高端、高效、高附加值的战略新兴产业转 变。进一步提高这些地区的经济效益是提升京津 冀城市群整体生态效率的有效途径。(2)冀中南地 区应整合科技创新资源, 促进生产工艺水平提升, 加快传统产业的转型升级, 严格控制重化工业产 能, 降低生产过程中大气污染物的排放强度。此 外, 县域间应强化生态建设和环境保护力度, 建立 生态同建、环境同治的联防联控生态环境保护机 制。弱化这些地区的环境影响是提升地区生态效 率的关键。(3)冀西北和东南部地区应在巩固生态 建设和环境保护已有成果基础上, 控制经济开发强 度, 优化开发方式, 加强产业集聚区建设, 完善产业 链布局, 推动生态产业发展, 提高经济效益, 最终实 现生态效率的提升。

\section{参考文献(References)}

方创琳, 周成虎, 顾朝林, 等. 2016. 特大城市群地区城镇化 与生态环境交互耦合效应解析的理论框架及技术路径 [J]. 地理学报, 71(4): 531-550. [Fang C L, Zhou C H, Gu C L, et al. 2016. Theoretical analysis of interactive coupled effects between urbanization and eco- environment in mega- urban agglomerations[J]. Acta Geographica Sinica, 71(4): 531-550.]

关伟, 许淑婷. 2015. 中国能源生态效率的空间格局与空间 效应 [J]. 地理学报, 70(6): 980-992. [Guan W, Xu S T. 2015. Study on spatial pattern and spatial effect of energy eco- efficiency in China[J]. Acta Geographica Sinica, 70 (6): 980-992.]

韩瑞玲, 佟连军, 宋亚楠. 2011. 基于生态效率的辽宁省循环 经济分析 [J]. 生态学报, 31(16): 4732-4740. [Han R L, Tong L J, Song Y N. 2011. Analysis of circular economy of Liaoning Province based on eco-efficiency[J]. Acta Ecologica Sinica, 31(16): 4732-4740.]

胡彪, 付业腾. 2016. 中国生态效率测度与空间差异实证: 基 于 SBM 模型与空间自相关性的分析 $[\mathrm{J}]$. 干旱区资源与环 境, 30(6): 6-12. [Hu B, Fu Y T. 2016. The measure and the spatial disparity analysis of eco- efficiency in China[J]. Journal of Arid Land Resources and Environment, 30(6): 612.]

李惠娟, 龙如银, 兰新萍. 2010. 资源型城市的生态效率 评价 [J]. 资源科学, 32(7): 1296-1300. [Li H J, Long R Y, Lan X P. 2010. Assessment for eco-efficiency of resource- based cities[J]. Resources Science, 32(7): 12961300.]

陆大道. 2015. 京津冀城市群功能定位及协同发展 $[\mathrm{J}]$. 地理 科学进展, 34(3): 265-270. [Lu D D. 2015. Function orientation and coordinating development of subregions within the Jing-Jin-Ji Urban Agglomeration[J]. Progress in Geography, 34(3): 265-270.]

马雪莹, 邵景安, 徐新良. 2016. 基于熵权-TOPSIS 的山区乡 镇通达性研究: 以重庆市石柱县为例 $[\mathrm{J}]$. 地理科学进展, 35(9): 1144-1154. [Ma X Y, Shao J A, Xu X L. 2016. Rural transportation accessibility in mountainous areas based on the entropy-weight TOPSIS method: A case study of Shizhu County, Chongqing Municipality[J]. Progress in Geography, 35(9): 1144-1154.]

潘丹, 应瑞瑶. 2013. 中国农业生态效率评价方法与实证: 基 于非期望产出的 SBM 模型分析 [J]. 生态学报, 33(12): 3837-3845. [Pan D, Ying R Y. 2013. Agricultural eco-efficiency evaluation in China based on SBM model[J]. Acta Ecological Sinica, 33(12): 3837-3845.]

涂正革, 刘磊珂. 2011. 考虑能源、环境因素的中国工业效率 评价: 基于 SBM 模型的省级数据分析 $[\mathrm{J}]$. 经济评论, (2): 55-65. [Tu Z G, Liu L K. 2011. Efficiency evaluation of industrial sectors in China accounting for the energy and environment factors: Based on provincial data by a SBM ap- 
proach[J]. Economic Review, (2): 55-65.]

Arabi B, Munisamy S, Emrouznejad A, et al. 2014. Power industry restructuring and eco- efficiency changes: A new slacks-based model in Malmquist-Luenberger index measurement[J]. Energy Policy, 68(2): 132-145.

Cerutti A K, Beccaro G L, Bagliani M, et al. 2013. Multifunctional ecological footprint analysis for assessing ecoefficiency: A case study of fruit production systems in Northern Italy[J]. Journal of Cleaner Production, 40: 108117.

Division D. 2010. Eco- efficiency indicators: Measuring resource- use efficiency and the impact of economic activities on the environment[C]//eSocialSciences. Bangkok, Thailand: Economic and Social Commission for Asia and the Pacific.

Egilmez G, Yong S P. 2014. Transportation related carbon, energy and water footprint analysis of U.S. manufacturing: An eco- efficiency assessment[J]. Transportation Research Part D: Transport and Environment, 32: 143-159.

Frischknecht R. 2010. LCI modelling approaches applied on recycling of materials in view of environmental sustainability, risk perception and eco-efficiency[J]. The International Journal of Life Cycle Assessment, 15(7): 666-671.

Geddes J A, Martin R V, Boys B L, et al. 2016. Long-term trends worldwide in ambient $\mathrm{NO}_{2}$ concentrations inferred from satellite observations $[\mathrm{J}]$. Environmental Health Perspectives, 124(3): 281-289.

Gurauskienė I, Stasiškienė Ž. 2011. Application of material flow analysis to estimate the efficiency of e-waste management systems: The case of Lithuania[J]. Waste Management \& Research, 29(7): 763-777.

Hahn T, Figge F, Liesen A, et al. 2010. Opportunity cost based analysis of corporate eco-efficiency: A methodology and its application to the $\mathrm{CO}_{2}$-efficiency of German companies [J]. Journal of Environmental Management, 91(10): 19972007.

Huang J H, Yang X G, Cheng G, et al. 2014. A comprehensive eco-efficiency model and dynamics of regional eco- efficiency in China[J]. Journal of Cleaner Production, 67: 228238.

Huppes G, Ishikawa M. 2005. A framework for quantified ecoefficiency analysis[J]. Journal of Industrial Ecology, 9(4): 25-41.

Li D Z, Zhu J, Hui E C M, et al. 2011. An emergy analysis- based methodology for eco-efficiency evaluation of building manufacturing[J]. Ecological Indicators, 11(5): 14191425.

Li G D, Fang C L, Wang S J, et al. 2016. The effect of economic growth, urbanization, and industrialization on fine particulate matter (PM2.5) concentrations in China[J]. Environmental Science \& Technology, 50(21): 11452-11459.

Lin J Y, Li Y, Wang W, et al. 2010. An eco-efficiency-based urban sustainability assessment method and its application [J]. International Journal of Sustainable Development \& World Ecology, 17(4): 356-361.

Liu Y, Wang W, Li X Q, et al. 2010. Eco-efficiency of urban material metabolism: A case study in Xiamen, China[J]. International Journal of Sustainable Development \& World Ecology, 17(2): 142-148.

Plehn J, Sproedt A, Gontarz A, et al. 2012. From strategic goals to focused eco-efficiency improvement in production- bridging the gap using environmental value stream mapping[C]//10th Global Conference on Sustainable Manufacturing. Zürich, Switzerland: Eidgenössische Technische Hochschule Zürich, Institute of Machine Tools and Manufacturin: 251-264.

Quariguasi-Frota-Neto J, Bloemhof J. 2012. An analysis of the eco-efficiency of remanufactured personal computers and mobile phones[J]. Production and Operations Management, 21(1): 101-114.

Burritt R, Schaltegger S. 2001. Eco- efficiency in corporate budgeting[J]. Environmental Management \& Health, 12 (2): 158-174.

Tone K. 2001. A slacks-based measure of efficiency in data envelopment analysis[J]. European Journal of Operational Research, 130(3): 498-509.

van Donkelaar A, Martin R V, Brauer M, et al. 2016. Global estimates of fine particulate matter using a combined geophysical- statistical method with information from satellites, models, and monitors[J]. Environmental Science \& Technology, 50(7): 3762-3772.

Wachsmuth D, Cohen D A, Angelo H. 2016. Expand the frontiers of urban sustainability[J]. Nature, 536: 391-393.

Yin K, Wang R S, An Q X, et al. 2014. Using eco-efficiency as an indicator for sustainable urban development: A case study of Chinese provincial capital cities[J]. Ecological Indicators, 36: 665-671.

Yu Y D, Chen D J, Zhu B, et al. 2013. Eco-efficiency trends in 
China, 1978- 2010: Decoupling environmental pressure from economic growth[J]. Ecological Indicators, 24: 177184.
Zhang Y, Yang Z F, Liu G Y, et al. 2011. Emergy analysis of the urban metabolism of Beijing[J]. Ecological Modelling, 222(14): 2377-2384.

\title{
Spatial pattern and evaluation of eco-efficiency in counties of the Beijing-Tianjin-Hebei Urban Agglomeration
}

\author{
REN Yufei ${ }^{1}$, FANG Chuanglin ${ }^{2 *}$ \\ (1. College of Resource Environment and Tourism, Capital Normal University, Beijing 100048, China; \\ 2. Institute of Geographic Sciences and Natural Resources Research, CAS, Beijing 100101, China)
}

\begin{abstract}
Urbanization in China has resulted in an increased consumption of resources, energy, and materials and led to negative environmental effects. Urban agglomeration plays pivotal roles in the China's new urbanization. These factors have motivated the widely discussed topic of urban agglomeration's eco-efficiency. This research developed an index system of eco-efficiency and evaluated the eco-efficiency of counties in the Beijing- Tianjin- Hebei Urban Agglomeration using the modified Topsis model for the spatial pattern of consumption of resources, economic benefit, and environmental pollution outputs. We also quantified ecoefficiency by the undesirable- output SBM model in 2006, 2010, and 2014 using environmental pollution as an undesirable output. Spatial autocorrelation index and local Moran's $I$ index were used to analyze the spatial correlation pattern of eco- efficiency at the county level in the study area. The results show that there exist significant spatiotemporal differences of consumption of resources, economic benefit, and environmental pollution outputs. The Beijing-Tianjin-Hebei area had high values of inputs and outputs in the research period. Eco-efficiency of counties in the Beijing-Tianjin-Hebei Urban Agglomeration was relatively low. Mean values of eco-efficiency were $0.324,0.305$, and 0.347 in 2006, 2010, and 2014. It decreased first and then increased. The reasons for the spatial differences of eco-efficiency are location and natural backgrounds, and low economic benefit and high environmental impact are the main factors that restrict the improvement of eco-efficiency. The global Moran's $I$ index values were $0.2539,0.3007$, and 0.3088 , indicating that the impact factors of ecoefficiency were not only related to the economic development level of each county unit, but also associated with the eco-efficiency of adjacent counties. The positive agglomeration effect has been increasingly obvious since 2006, and the gap of eco-efficiency of neighboring counties has reduced.
\end{abstract}

Key words: eco- efficiency; modified TOPSIS model; undesirable-SBM model; spatial correlation pattern; county; Beijing-Tianjin-Hebei Urban Agglomeration 